
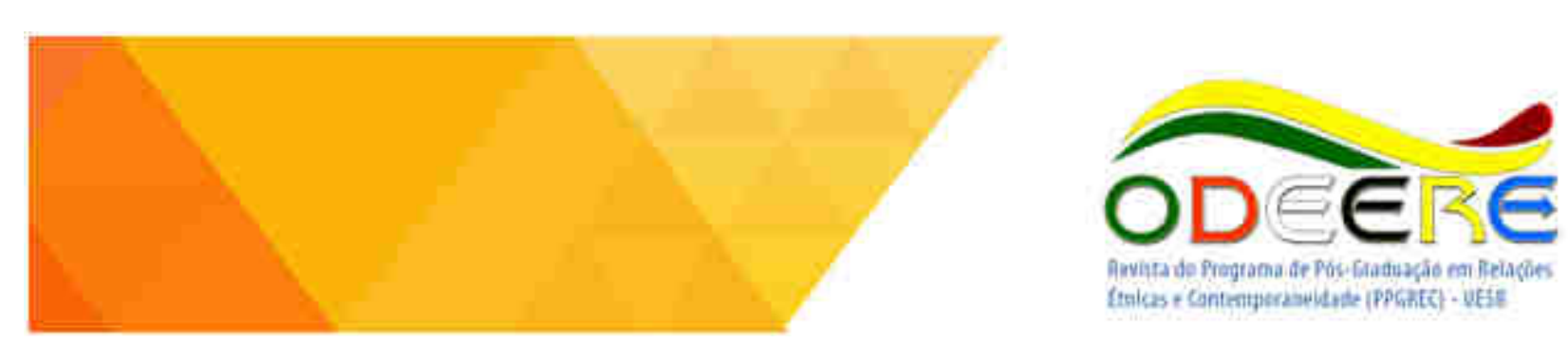

\section{A memória do}

Itarendá

\section{ressignificando}

\section{novas}

\section{territorialidades}

\author{
Evilania Bento da Cunha \\ Universidade Federal do Amapá (UNIFAP) \\ evilaniageo@yahoo.com.br
}

\section{Rosilene Cruz de Araújo}

Universidade Federal do Amapá (UNIFAP)

anhamona.tuxa@hotmail.com

\section{DOI: 10.22481/odeere.v3i5.3640}

Resumo: O presente relato é resultado dos estudos na disciplina Antropologia Visual, ministrada pelo professor Dr. Flavio Leonel no Programa de mestrado em Linguagens e Saberes na Amazônia da Universidade Federal do Pará, Campus de Bragança. Diante da fundamentação teórica apreciada durante a disciplina pensamos discutir o conceito de memória apresentado por Paul Ricoeur, em que o autor baseia-se em duas perguntas: de que há lembrança? De quem é a memória? Podemos atribuir a esses questionamentos a passagem de paradigma: do fato que é lembrado, ao sujeito que lembra tal fato. Dessa forma, a memória dos Ka'apor pode remeter a imagens do passado e reconstituir o presente das novas aldeias criadas dentro do seu Território. Assim, o relato fará um recorte teórico de conceitos chaves no desenvolvimento da pesquisa, cujo tema é $A$ (RE)SIGNIFICAÇÃO DO LUGAR E AS NOVAS TERRITORIALIDADES DOS KA'APOR NAS ALDEIAS XIÉ PYHÚN RENDA, PARAKUY RENDA E TURIZINHO.

Palavras-Chave: Resignificação, aldeias, Itarendá

A memória nos remete à imagem, isso porque o ato de memorizar ou de relatar fatos conservados na memória traz consigo imagens do passado, sendo o relato uma forma de resgate dessas imagens contidas na memória individual ou coletiva, "representamos um acontecimento passado cuja imagem possuímos" ${ }^{1}$.

\footnotetext{
${ }^{1}$ RICOEUR, Paul. A memória, a história, o esquecimento. Tradução Alain François (et al). Campinas,SP: Editora da Unicamp, 2007.
} 
Na pesquisa de mestrado, intitulada A (re)significação do lugar e as novas territorialidades dos Ka'apor nas aldeias Xié pyhún renda, Parakuy renda e Turizinho, busco compreender se a ressignificação das novas aldeias, se tem elementos da antiga aldeia Itarendá e quais desses elementos eles trouxeram, neste caso se os topônimos dados aos novos lugares tem relação com a antiga aldeia que habitavam.

É mister considerar que esta pesquisa teve seu embrião numa atividade didática na área curricular de História e Geografia durante a avaliação cognitiva com estudantes Ka'apor em 2012. A avaliação foi resultado de uma demanda detectada nos encontros de educação Ka'apor em que eles perceberam a necessidade de registro de processos avaliativos na educação escolar indígena nas aldeias, e ainda serviria como subsídio para o projeto Ka'a namõ jumu'e há katu, correspondente a Educação Básica Ka'apor.

Durante a primeira avaliação cognitiva, em agosto de 2012, na aldeia Zé Gurupi, com 66 estudantes oriundos de oito aldeias do Território Alto Turiaçu, foi desenvolvida uma atividade na qual os estudantes Ka'apor desenhavam os marcos que consideravam importantes na sua história pessoal e coletiva por década. A proposta da atividade foi apresentada as duas turmas. A primeira seguiu as indicações e todos desenharam ou opinaram na linha do tempo formada por folhas de cartolinas; já a segunda turma se dividiu em grupos por décadas e, embora a orientação tenha sido a mesma, o entendimento seguiu execuções diferentes.

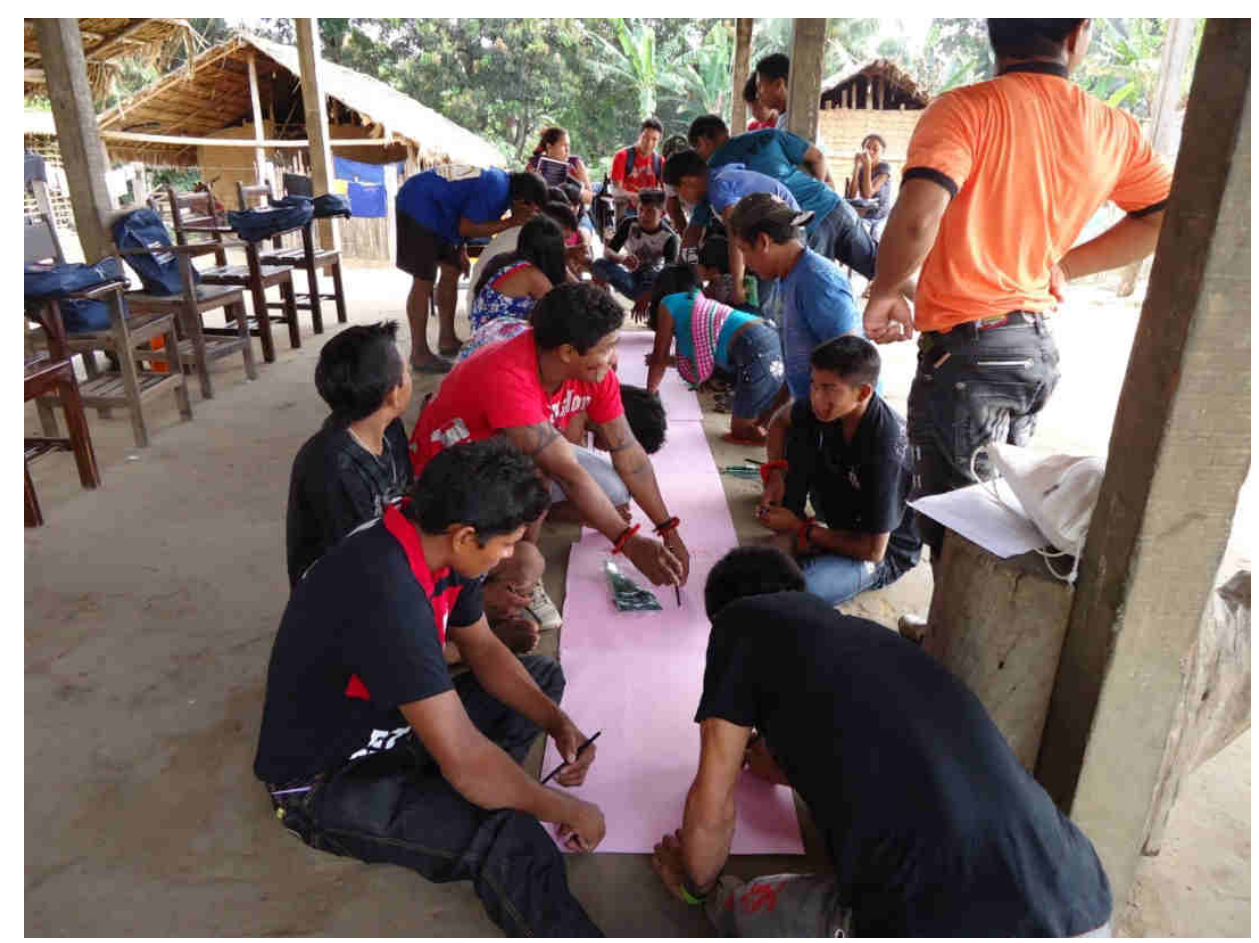

Figura 1: Atividade linha do tempo e da vida

Fonte: Cunha, Evilania Bento da. 2012 
Após a construção da linha do tempo, cada estudante expôs para a turma o evento que considerou relevante para ele e para sua comunidade. Foi a partir da escuta destes marcos simbólicos que identifiquei a saudade e a lembrança do Itarenda. Todos os estudantes que viveram nesta aldeia e foram reterritorializados nas aldeias Xié pyhun renda, Parakuy renda e Turizinho relatavam a maravilha de morar no Itarenda por que, segundo eles, lá era muito bom, tinha caça, floresta preservada, pássaros, pedras e era muito bonito, mas precisaram mudar-se para proteger o Território da invasão dos fazendeiros e madereiros, identificaram também que o desmatamento era muito ruim para eles pois a caça estava ficando cada vez mais distante ${ }^{2}$.

Dessa forma, representamos um acontecimento passado cuja imagem já temos, porém precisa estar atentos para não fazer da memória uma província da imaginação, "uma imagem não pode se constituir sem um saber que a constitua" ${ }^{3}$. Sendo assim, observa-se nas imagens que os estudantes desenharam um mapa mental de percurso feito em torno da aldeia, um saber inerente a cada um/uma sobre o espaço, e representado a partir da imagem construída pela observação desse espaço.

A memória torna-se seletiva no momento em que o sujeito escolhe imagens para representar a realidade do objeto ausente. A representação se dá num jogo de escolhas entre o que colocar e o que deixar de fora, passando pela subjetividade e pela intenção do que mostrar e para quem mostrar. Passamos da palavra dirigida à palavra atribuída/emprestada aos artefatos ${ }^{4}$. Assim, a floresta, a caça, os pássaros, o formato e distribuição das moradias manifestam uma presença, ou uma ausência-presença, ou seja, presente na memória, mas ausente materialmente nos seus constructos físicos.

Assim, alguns saberes pertencem aos Ka'apor e outros se deram a partir do contato com a sociedade ocidental. De acordo com o Parecer Interdiciplinar elaborado posteriormente à Avaliação Diagnóstica em 2012, foi apontado que nos componentes curriculares de Geografia e História, a noção de territorialidade deve ser construída levando em consideração que os conceitos de 'internacional' e 'nacional', por exemplo, não se aplicam às noções em Ka'apor. Desse modo, é necessário encontrar outros termos para correlacionar as escalas local, regional, nacional e internacional. Por outro lado, percebe-se uma apreensão das noções básicas de

\footnotetext{
${ }^{2} \mathrm{O}$ relato dos estudantes durante as aulas faz parte da minha memória enquanto educadora, por isso escolhi citar do modo como eles se expressaram em suas explicações.

${ }^{3}$ SARTRE, Jean paul. 0 imaginário: psicologia fenomenologica da imaginação. Tradução Duda Machado. São Paulo: Ática, 1996, p. 84.

${ }^{4}$ SEVERI, Carlo. A palavra emprestada ou como falam as imagens. Revista de Antropologia, São Paulo, USP, 2(52): 459-506, 2009.
} 
cartografia através do reconhecimento e reprodução do território, de orientação no espaço por meio de constructos naturais ou antropizados, como os rios e estradas.

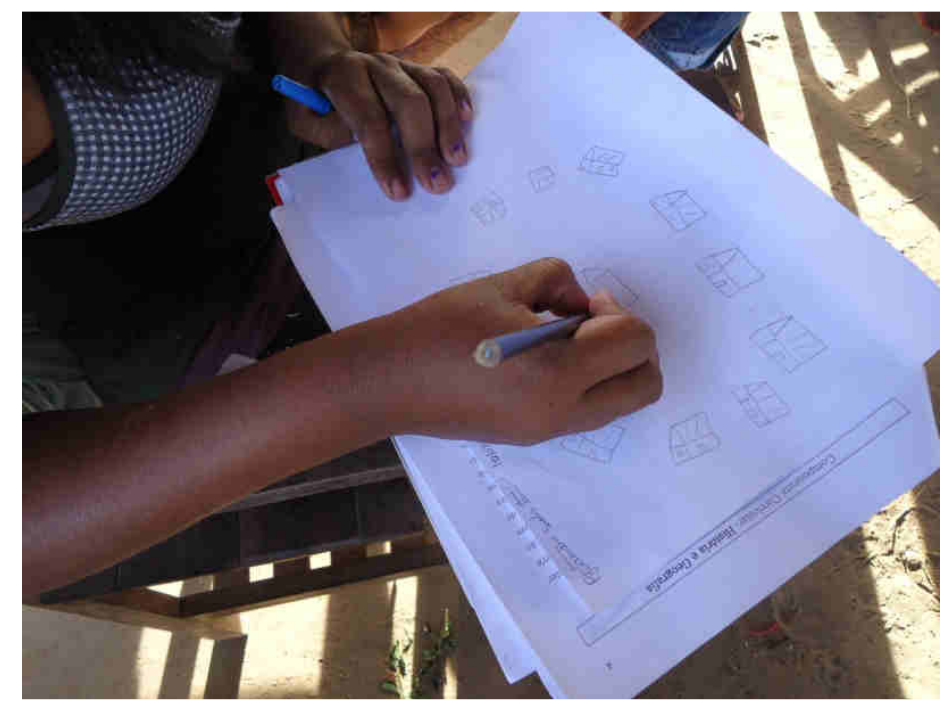

Figura 2: Atividade de mapa mental da aldeia durante a avaliação diagnostica Fonte: Cunha, Evilania Bento da. 2012

Além disso, os educandos Ka'apor relatam histórica e espacialmente fatos que desencadeiam transformações culturais e territoriais com muita propriedade por se tratar de experiências vividas.

No processo de contato dos indígenas com a sociedade ocidental foram sendo absorvidas algumas técnicas, sobretudo na prática das escolas indígenas, considerando que a escola é uma instituição da sociedade ocidental, suas práticas eram transferidas para escola indígena. Dessa forma, distinguimos conceitualmente as três fases ou experiências educacionais com os grupos indígenas no Brasil. 1. Educação Indígena, 2. Escola Indígena e 3. Educação Escolar Indígena.

$\mathrm{Na}$ educação indígena, toda a comunidade é formadora, e os conhecimentos são transmitidos de geração em geração, pautando-se na transmissão oral e prática dos seus costumes. É natural que a criança aprenda com os pais, contudo, as crianças indígenas aprendem brincando o que constitui o trabalho dos adultos, não sendo necessário ensinar com palavras, mas apenas com a presença.
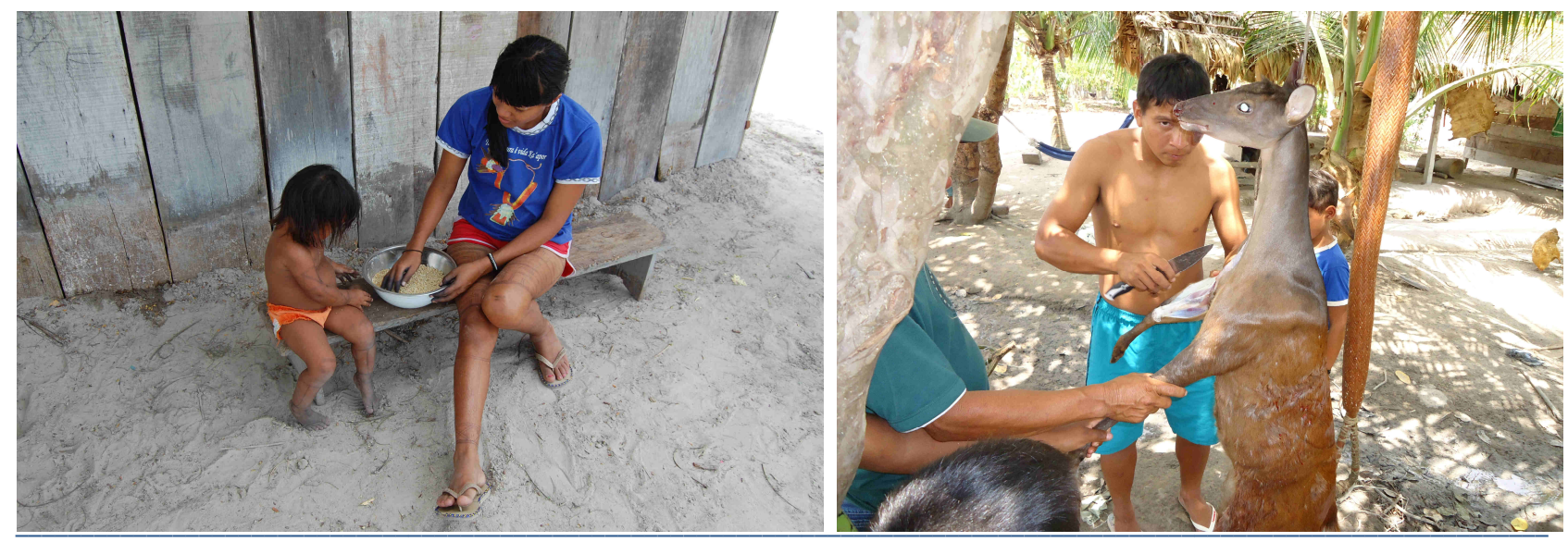

Odeere: Revista do Programa de Pós-Graduação em Relações Étnicas e Contemporaneidade - UESB. ISSN: 2525-4715 - Ano 2018, Volume 3, número 5, Janeiro - Junho de 2018. 
Figura 3: Educação dos fazeres tradicionais, as crianças aprendem com os pais Fonte: Sara Chena, 2013.

Durante a alternância de estudo em 2013 na aldeia Xié Pihun renda foram interrompidas as atividades de estudo por um dia para manutenção alimentar, uma vez que a secretaria estadual de educação não forneceu a alimentação e no cotidiano das comunidades sua subsistência provém da caça e da pesca e envolve toda a família.

No que se refere à Escola Indígena, o contato dessas sociedades com os colonizadores interferiu em seus costumes, fazendo-se necessárias escolas nas aldeias, a fim de ensinar às crianças o exigido pela sociedade moderna sem perder sua cultura e seus valores. A educação aplicada pelos jesuítas não considerava a cultura aqui existente, nem mesmo os aspectos naturais dessa terra; ensinava-se com o mesmo currículo de Portugal, e ainda há resquício disso hoje. Neste período a educação confundia-se com catequização, uma vez que a iniciação à leitura e escrita se dava para alcançar os objetivos da evangelização. A implementação de projetos escolares para as populações indígenas é tão antiga quanto os primeiros agentes coloniais no Brasil. Estas atividades escolares se desenvolveram de forma sistemática e planejada.

Na escola indígena predomina o formato da escola ocidental dentro de um padrão universal. Independente do lugar e do público a frequentar essa escola. o reconhecimento do saber passava pelo crivo do professor, que muitas vezes era o missionário. Esse formato de escola ainda se aplica em algumas comunidades disputando espaço com a Educação Escolar Indígena.

Já a Educação Escolar Indígena, surge num contexto de encontros e assembleias em que os povos indígenas refletem seu papel em meio ao seu povo. Na década de 80 , os indígenas assumem as salas de aula de suas escolas: pode-se dizer que é a educação dos índios para os índios. Com isso vão surgir diversas organizações de professores como a Organização Geral dos Professores Ticuna Bilíngues - OGPTB, Comissão dos professores indígenas do Amazonas, Roraima e Acre - COPIAR, alargando a discussão nos encontros regionais e nacionais de Educação Escolar Indígena que foram tornando-se mais frequentes ${ }^{5}$. Os Ka'apor demoraram um pouco a terem sua própria organização de educação, contudo após vários encontros de formação foi sendo consolidada a Comissão de Educação Ka'apor, responsável pela organização do projeto de educação no qual os indígenas assumem a regência das turmas, não mais como intérpretes bilíngue, mas como agentes de sua própria educação. A proposta de elaboração do plano de atividade para cada área conclui com o seguinte texto:

\footnotetext{
${ }^{5}$ GRUPIONI, Luis Donizete Benzi (org.). Formação de professores indígenas: repensando trajetórias. Brasília: Ministério da Educação, Secretaria de Educação Continuada, Alfabetização e diversidade, 2006.
} 
O nosso $k a^{\prime} a$ é o lugar em potencial para o aprendizado Ka'apor. Aprendemos também com os animais, pássaros. Aprendemos na floresta, nos igarapés, a gente continua sendo Ka'apor. Depois que os Kamará estabeleceram o contato com nosso povo, passamos a ter no meio de nós a escola. Entendemos que esse espaço deve ser utilizado por nosso povo para garantir nossa identidade e projeto de vida enquanto Ka'apor. A escola deve servir para que nosso povo continue vivendo em nosso Território com dignidade. (Orientações para a elaboração do plano de atividades didático-pedagógicas).

Assim, a Educação Escolar Indígena, tem elementos da Educação Indígena e se apropria de elementos da Escola Indígena, porém com atualização didático-pedagógica e contextualização curricular, poderíamos dizer que é a escola do índio para o índio. Neste contexto, o saber é apropriado através da reflexão do fazer, do saber consciente do que se quer ensinar, do que os jovens ka'apor precisam apreender e ressignificar.

As fotografias retratam elementos do fazer e do ser de um povo registrando no tempo e no espaço memórias presentes ou não. Os Ka'apor conseguem por meio de técnicas de captação da imagem armazenar memórias do seu povo como desabrochou na história do Itarenda. Dessa forma, Fernando Tacca ${ }^{6}$ diz que:

A descoberta da imagem técnica, ou sua fixação, foi uma obsessão de homens da ciência em vários países simultaneamente, realizando pesquisas com materiais distintos, mas com perspectivas muito similares: uma imagem que poderia ser guardada, uma memória definitiva de pessoas, paisagens e coisas; uma memória aparelhística especular, programada por tecnologia aplicada, aparentemente limpa das imperfeições humanas.

A memória, no entendimento de Maurice Halbwachs ${ }^{7}$, está sempre relacionada a eventos de um grupo, por isso a distinção entre memória individual e coletiva não existe, uma vez que a memória está intrinsecamente ligada a um grupo social e, se por acaso esse grupo não reconhece a pertença de determinado membro, este também não comunga da memória coletiva desse grupo. O autor indica que as lembranças continuam coletivas, pois elas são lembradas pelos outros, conduzem a memória coletiva.

Observou-se que a memória coletiva dos Ka'apor aponta para a relação entre território e preservação da floresta, de modo que o movimento migratório ou de deslocamento tem como objetivo a defesa da mata. Como o território precisa estar resguardado para atingir esse objetivo, podemos inferir que a memória coletiva é produtora do território. Por outro lado, o território

\footnotetext{
${ }^{6}$ TACCA, Fernando de. Rituaes e festas Bororo: a construção da imagem do índio como "selvagem" na Comissão Rondon. Revista de antropologia, SÃO PAULO, USP, 1(45): 187-219, 2002.

7 HALBWACHS, Maurice. Memória Coletiva. Tradução de Laurent Léon Schaffter. São Paulo: edições Vértices. 1990.
} 
traduz relações de poder que configuram divisões espaciais, sendo fruto de relações materiais e simbólicas efetivadas pelos grupos nas disputas pela apropriação deste ${ }^{8}$.

A memória individual encontra-se na interface do coletivo, unindo diferentes grupos de uma sociedade em uma só memória, que serão tantas quantos os grupos dentro da sociedade. A memória suporta as percepções e representações dos homens acerca do mundo em que vivem e através da memória há um re-conhecimento do passado que organiza-se como representação, comunicando ao presente continuidades e rupturas que marcam o tempo-espaço do passado ao presente. $^{9}$

Dessa forma, o espaço, o tempo e as relações territoriais interferem na memória. Esses elementos têm seus conteúdos reconstruídos, cujas imagens e ideias são interpretadas pelos grupos, na medida em que são modelados e que levam em consideração as relações políticas e de poder estabelecidas no processo de apropriação espacial.

\section{IMAGEM E IMAGINARIO UM DIÁLOGO ENTRE AUTORES}

Ao abordar sobre a memória que os Ka'apor têm do Itarenda evocada durante atividade pedagógica foram utilizadas diversas imagens. Esse recurso, segundo Ana Luiza Rocha "trata-se do olhar de interioridade que a imagem, o imaginário projeta na produção do conteúdo intelectual do conhecimento científico", uma vez que a imagem não é figurativa, ela compõe o corpo do texto com uma linguagem visual. Assim, segundo a autora, as motivações simbólicas do pesquisador the permitem transformar os dados sensíveis, obtidos no trabalho de campo, em imagens-objetos de conhecimento. ${ }^{10}$

A pesquisa de Ana Luiza Rocha alerta para o fato de não transformar a produção e a criação de imagens como parte integrante do método de reflexão etnográfica no enquadramento do pensamento racionalista, já tão conhecida no âmbito das ciências humanas.

Assim sendo, é o caráter "indecifrável" da linguagem visual que configura a imagem-texto etnográfica e que a revela como parte integrante do patrimônio imaginário da humanidade, o que acaba "re-situando" etnógrafo e nativo como sujeitos-sede de representações simbólicas.

\footnotetext{
${ }^{8}$ FLAVIO, Luiz Carlos. Território e Memória. In: SAQUET, Marcos Aurélio (Org.). Estudos territoriais na ciência geográfica. São Paulo: Expressões. 2013.

${ }^{9}$ FLAVIO, Luiz Carlos. Território e Memória. In: SAQUET, Marcos Aurélio (Org.). Estudos territoriais na ciência geográfica. São Paulo: Expressões. 2013.

${ }^{10}$ ROCHA, Ana Luiza Carvalho da. Antropologia das formas sensíveis: entre o visível e o invisível, a floração de símbolos. In: Horizontes Antropológicos, Antropologia Visual, 1(2): 85-92, 1995.
} 
Com base nesse pensamento de, apresento o relato de Valdemar, uma liderança Ka'apor que durante nossa entrada para a aldeia Xié Pihun renda em setembro de 2013, quando nos propomos à missão de não fazer o motorista dormir, nos contou diversas histórias, das quais destaco uma que ficou registrada na minha lembrança pela linguagem simbólica que a envolve.

Seu Valdemar relatou que quando criança ficou muito doente com dor na garganta. Ele então com seus pais procurou o pajé, que foi fazendo várias perguntas de como tinha sido a semana dele, o que tinha feito e foram refazendo os passos, até chegar no dia que ele havia ido pescar, e não conseguia pegar nenhum peixe, pois só tinha piranha. Ele ficou com muita raiva e arrancou a cabeça da piranha e jogou de volta na água. O pajé disse que a dor de garganta dele era o espírito da piranha e que pra ele ficar bom precisava refazer o caminho de volta até o rio e pedir desculpas ao espírito da piranha, assim ele iria ficar curado, e segundo seu Valdemar ele ficou curado e nunca mais fez mal a outro animal. Aprendeu pela crença que seu povo pratica que só pode matar se for pra comer. Portanto, poderíamos dizer que a sabedoria, a religião, a crença contêm na sua essência uma resposta a falta de resposta.

O relato de Valdemar nos aponta para o rico papel do imaginário na produção da realidade etnográfico. O imaginário da crença nos espíritos da floresta e em todos os seres que nela habitam exige um nível de relação de respeito pelos seres presentes, pois todos têm alma. A imagem do espírito da piranha torna-se real a ponto de provocar a dor física, relacionando as partes do corpo da piranha com seu próprio corpo, a garganta. No imaginário coletivo Ka'apor os males físicos são resultados de males espirituais.

É mister pensar a realidade a partir do filtro do imaginário, mas não como contrários e sim complementares, uma vez que, o imaginário é, ao mesmo tempo, impalpável e real ${ }^{11}$. A entrevista que Michel Maffesoli concedeu a Juremir Machado da Silva, nos aponta o cerne do conceito de imaginário como uma "força social de ordem espiritual, uma construção mental, que se mantém ambígua, perceptível, mas não quantificável. A existência de um imaginário determina a existência de conjuntos de imagens. A imagem não é o suporte, mas o resultado."

Dessa forma, a lembrança do Itarenda como o lugar da prosperidade, onde se encontrava muita caça, da harmonia, onde todos eram felizes e não tinham contato com os não indígenas, não sabiam que existia um mundo muito grande aqui fora e talvez fosse bom que continuassem

\footnotetext{
${ }^{11}$ MAFFESOLI, Michel. O imaginário é uma realidade. Revista FAMECOS, Porto Alegre, 15: 74-82, 2001.
} 
sem saber, se transformou num imaginario coletivo. Pois, só existe imaginário coletivo, o imaginário é o estado de espírito de um grupo.

Pode-se ainda atribuir ao imaginário Ka'apor a sua chegada no atual Território, reconhecida e demarcada como Terra Indígena Alto Turiaçu. De acordo com Valdemar Ka'apor, estudante do CBH (Ciclo Básico de Habilidades), em relato durante aulas ministradas sobre o conteúdo Migração, eles viviam todos juntos no Xingu. Eram muitos índios e um dia eles saíram para caçar. Quando retornaram, a caça não foi suficiente para todos comerem, eles brigaram e os que comeram ficaram na terra e os que não comeram foram embora. Eles andaram muito e esse grupo se separou mais uma vez: uma parte do grupo atravessou o rio Amazonas e a outra o rio Gurupi chegando no Maranhão, foi assim que os Ka'apor chegaram na Terra Indígena Alto Turiaçu.

A imagem, no entanto, para Aumont ${ }^{12}$ é construída através do olhar que filtramos, tudo passa pela visão, o olhar é o que define a intencionalidade. Só há busca visual se houver projeto de busca consciente, meu olhar vai buscar o que eu quero ver. Além disso, a imagem é uma produção técnica captada a partir do globo ocular que percebe a realidade em etapas, pode-se dizer que a captação da imagem gera um mosaico na sequência que o observador priorizar. O autor ressalva que as imagens são produzidas em duas dimensões, mas a vemos em três dimensões, a imagem retrata objetos ausentes que nos conduzem ao simbólico. A visão, portanto, torna-se o portal para percepções e interpretações da realidade.

Já Tacca $^{13}$ aborda o imaginário como imaginário social, faz-se por meio das representações codificadas da realidade, prática normatizada pelas relações sociais. "Como uma caixa preta, as imagens mentais conscientes ou inconscientes relacionam-se de uma forma ambígua com as imagens reais, entendidas aqui como imagens naturais: captadas pelos órgãos visuais." A imagem mental é construída por todos nossos mecanismos perceptivos, assim como as outras percepções são também interfaces de um processo de conhecimento.

\section{ALGUMAS CONSIDERAÇÕES}

A primeira consideração é que a memória do Itarendá consolida-se dentro do imaginário coletivo e que a existência dessa aldeia e tudo que foi vivido lá, é um elemento de força para continuar lutando por uma Terra sem invasores, com fartura, onde as crianças possam crescer

\footnotetext{
${ }^{12}$ AUMONT, Jacques. Do visual ao imaginário. In: A Imagem. Campinas: Papirus, 1993, pp. 58-76.

13 TACCA, Fernando de. Imagem fotográfica: aparelho, representação e significação. Psicologia \& Sociedade, 17 (3): 09-17, 2005.
} 
livres de perseguição. E ainda, uma vez deixado o lugar considerado da harmonia com a natureza, estão impelidos a irem a qualquer parte dentro do seu Território para terem de volta o equilíbrio.

A segunda consideração é que o projeto de educação Ka'apor desperta memórias adormecidas no bojo de parentes que nem se conheciam. Através da Educação Escolar Ka'apor faz desabrochar elementos do imaginário como as cantorias, provocando nos jovens participantes do projeto o interesse e aprofundamento da cultura, gerando novas imagens e ressignificando antigas imagens.

A terceira consideração é que a definição e escolha das imagens para compor esse texto foi uma segunda reflexão a partir e além dos autores que fundamentaram os conceitos de memória e imagem. Além de me permitir perceber minhas escolhas ao fotografar, percebi também que nem sempre essas escolhas são conscientes, do ponto de vista ideológico, posso acreditar e defender ideologiamente posições que contradizem com minha prática, muitas vezes embuídas de ideias que permearam o meu processo de aprendizagem, mas após uma reflexão consciente não os aceito mais. No entanto, na sutileza e na dialética do ser, muitas vezes têm-se atitudes que não corresponde ao que se acredita.

\section{REFERÊNCIAS}

AUMONT, Jacques. Do visual ao imaginário. In: A Imagem. Campinas: Papirus, 1993, pp. 5876.

BARBOSA, Luiz Bueno Horta(org.). O problema indígena no Brasil. Rio de Janeiro: Imprensa Nacional- Brasil. 1947.

FLAVIO, Luiz Carlos. Território e Memória. In: SAQUET, Marcos Aurélio (Org.). Estudos territoriais na ciência geográfica. São Paulo: Expressões. 2013.

GRUPIONI, Luis Donizete Benzi (org.). Formação de professores indígenas: repensando trajetórias. Brasília: Ministério da Educação, Secretaria de Educação Continuada, Alfabetização e diversidade, 2006.

HALBWACHS, Maurice. Memória Coletiva. Tradução de Laurent Léon Schaffter. São Paulo: edições Vértices. 1990.

MAFFESOLI, Michel. O imaginário é uma realidade. Revista FAMECOS, Porto Alegre, 15: 7482, 2001.

RICOEUR, Paul. A memória, a história, o esquecimento. Tradução Alain François (et al). Campinas,SP: Editora da Unicamp, 2007.

ROCHA, Ana Luiza Carvalho da. Antropologia das formas sensíveis: entre o visível e o invisível, a floração de símbolos. In: Horizontes Antropológicos, Antropologia Visual, 1(2): 85-92, 1995.

Tecnologias Audiovisuais na Construção de Narrativas Etnográficas: um percurso de investigação. Campos, 4:113-134, 2003.

SARTRE, Jean paul. 0 imaginário: psicologia fenomenologica da imaginação. Tradução Duda Machado. São Paulo: Ática, 1996. 
SEVERI, Carlo. A palavra emprestada ou como falam as imagens. Revista de Antropologia, São Paulo, USP, 2(52): 459-506, 2009.

TACCA, Fernando de. Rituaes e festas Bororo: a construção da imagem do índio como "selvagem" na Comissão Rondon. Revista de antropologia, SÃO PAULO, USP, 1(45): 187-219, 2002. Sociedade, 17 (3): 09-17, 2005.

. Imagem fotográfica: aparelho, representação e significação. Psicologia \& . O índio na fotografia brasileira: incursões sobre a imagem e o meio. História, Ciências, Saúde - Manguinhos, Rio de Janeiro, 1(18): 191-223, 2011.

Evilania Bento da Cunha: Professora da Universidade Federal do Amapá, Campus Binacional do Oiapoque, atua na área de Geografia - Ciências Humanas no curso de Licenciatura Intercultural Indígena. Possui graduação em Licenciatura em Geografia pela UESC, Especialização em Pedagogia da Alternância e educação do Campo pela UFMG, Mestre em Linguagens e Saberes na Amazônia pela UFPA, atua na área de Memória e Saberes, é Doutoranda no programa de Pós-graduação em Geografia da UFPA, cadastrada na Linha de Pesquisa Dinâmicas Territoriais na Amazônia. Foi professora de Geografia na educação escolar indígena ka'apor - SECRETARIA DE EDUCAÇÃO E CULTURA DO MARANHÃO, professora de geografia nas escolas Famílias Agrícolas de São João do arraial e Pedro II - Piauí, conselheira da Associação da Escolas Famílias Agrícolas do Piauí - AEFAPI, Educadora Popular voluntária da Rede de Educação Cidadã - RECID. atuando principalmente nos seguintes temas: Educação Escolar Indígena, Ensino de Geografia, Território/territorialidade, Educação do Campo e Pedagogia da Alternância.

Rosilene Cruz de Araújo: Possuo Graduação em História pela Universidade de Pernambuco - UPE (1996), Graduação em Licenciatura Intercultural em Educação Escolar Indígena - Ciências Matemática e da Natureza pela Universidade do Estado de Mato Grosso - UNEMAT (2006), Especialização em História do Brasil pelo Centro de Ensino Superior do Vale do São Francisco CESVASF (2006) e Mestrado em Educação e Contemporaneidade pela Universidade do Estado da Bahia - UNEB (2011). Atualmente sou Professora do Magistério Superior, Dedicação Exclusiva da Universidade Federal do Amapá, com a função de Coordenadora do Curso de Licenciatura Intercultural Indígena Campus Binacional de Oiapoque; atuo na Área de Ciências Humanas e Educação; Presidente do Núcleo Docente Estruturante do Curso de Licenciatura Intercultural Indígena; Membro do Conselho Universitário do Campus Binacional do Oiapoque/UNIFAP. Desenvolve pesquisa com povos indígenas, atuando como pesquisadora indígena do OPARÁ: Centro de Pesquisas em Etnicidades, Movimentos Sociais e Educação da Universidade do Estado da Bahia - UNEB e pesquisadora do Grupo de Estudos, Pesquisa e Práticas em Educação Intercultural em Ciências da Natureza e Matemática - GECIM da Universidade Federal do Amapá UNIFAP.

Artigo recebido para publicação em: Março de 2018.

Artigo aprovado para publicação em: Maio de 2018. 